\title{
EDITORIAL
}

\section{Factor de Impacto y retos de las publicaciones de la AEN.}

\author{
Iñaki Markez \\ Director Norte de Salud Mental
}

Nos hemos de remontar a 1955 cuando Eugene Garfield creó el factor de impacto (FI), como instrumento de valoración de las publicaciones científicas, fundando años después el Science Citation Index (SCI) en Filadelfia, principal repositorio internacional. Factor de impacto para medir la repercusión de los trabajos publicados que, más tarde, sería para evaluar a grupos de investigación, instituciones y a científicos autores, y cuya generalización de uso ha llegado a modificar los hábitos de citación y publicación en la autoría al objeto de un mayor reflejo en la SCI. Usos para los cuales no fue concebido el FI. El SCI era una publicación que incluía unos cientos de revistas académicas, que perseguía comprobar los vínculos entre investigadores ¿Cómo? A través de las citaciones. A Garfield se le ocurrió una fórmula para determinar el "factor de impacto" de las revistas científicas y ser elemento de ayuda para seleccionar en qué revistas publicar. El FI definido como el número promedio de veces que los artículos de una revista publicados en los dos años previos han sido citados en el presente año. Ese es el numerador de la fórmula y el denominador es el número de "artículos originales de investigación y artículos de revisión" publicados, con su arbitraria asimetría pues en el numerador se incluye cualquier tipo de contenido pero en el denominador solo irán los artículos citables.

Además son muy escasas las publicaciones no anglosajonas en el SCI lo que limita su uso para la medida de la repercusión real de las publicaciones fuera de ese ámbito monopolizador y restrictivo en la producción científica, siendo revistas latinoamericanas quienes ocupan las últimas posiciones en rankings de sus respectivas categorías. Llega a ser preocupante la obsesividad de la cuestión del impacto e igualmente preocupante el acriticismo ante un indicador que lo que valora es el número de citas por las revistas que forman parte de su base de datos, no del resto.

Hay que publicar mucho, en ocasiones de escaso interés, artículos con frecuencia replicados, con algunas variaciones en la muestra, con los mismos pacientes que participan en sucesivos estudios para poder publicar en pósteres, en revistas de impacto, en notas clínicas o en otras revistas menores. Bailando la autoría, con infinidad de autores con difícil coordinación de tareas: Tenemos que publicar mucho, para ser visibles en el mundillo universitario, tener méritos para la 
OPE o competir con mis iguales. Hay que publicar aunque no haya nada nuevo que aportar, la relevancia o el interés poco importan. En la hipertrofia de publicaciones y de trabajos, no siempre inéditos, con frecuencia se publica por exigencias curriculares, por rivalidades profesionales o de grupos de investigación, para obtención de fondos de financiación, para mayor resonancia académica, etc. Todo ello puede estar alejado de criterios de rigor científico y sí con elementos para lograr un FI más elevado como ocurre con las citaciones que dependen de la visibilidad en internet o en los medios de comunicación, potenciar la autocitación del autor, revistas que promueven referenciar a la propia publicación con orientaciones endogámicas, eliminación de casos clínicos pues raramente son citados y reducen el FI, así como promover las cartas al editor, las revisiones sistemáticas o los "artículos calientes" de interés o polémicos en un momento dado que favorecen la mayor citación o también publicar artículos de autores muy citados.

Desde muchos sectores y autores se cuestiona la utilidad del FI como instrumento evaluador de un artículo. Son muchos los trabajos en revistas de alto FI que no se citan nunca, y las opiniones de que tampoco es válido para evaluar a autores pues la cantidad de citaciones no se correlaciona con la calidad de la investigación $\mathrm{y}$, sin embargo, las perversiones de su uso como medida de calidad permanecen.

Una publicación científica debiera tener su razón de ser en la mayor profundización y proyección en la comunidad científica y social de los nuevos conocimientos tras muchas reflexiones, debates e investigaciones, pero la realidad va, en no pocas ocasiones, por otros derroteros. Así, el FI no debiera ser el fin primero de una revista científica pero, sin embargo, la mayoría compite por lograrlo. El FI es un indicador de visibilidad, valora el aislamiento según las referencias del propio país de la revista, de contemporaneidad, y sobre todo es un índice de confianza y prestigio de la publicación. También puede ser un elemento distorsionador, llegando a tener más valor aparecer como quinto o sexto firmante en un artículo en revista de impacto que una tesis doctoral ¡Qué cosas!

Hoy por hoy un estudio de las referencias citadas nos orientará sobre la accesibilidad y el consumo de la información en ciertas fuentes bibliográficas y también orientará sobre contextos intelectuales de los autores pero no sobre la calidad del producto. Una publicación científica no es solo una selección de artículos de contenidos interesantes. También debiera ser el resultado de un proceso donde la calidad se ha basado en la evaluación de suficiencia de los trabajos por profesionales competentes. Por eso, el rechazo de artículos no debe interpretarse que son "malos" sino que no son adecuados para esa revista en un momento dado según criterio del equipo editorial y sus revisores.

Por todo esto, cada vez van surgiendo más voces sobre la necesidad de ajuste del impacto en la producción científica mediante nuevos indicadores de calidad. De 
EDITORIAL

hecho, en la medida que haya nuevas bases bibliográficas y muchas más publicaciones accesibles como Google Scholar o PubMed nos iremos encontrando con que las instituciones académicas y científicas irán evaluando la calidad con otras medidas, seguro que alejadas de este factor tan poco riguroso.

Si la Asociación Española de Neuropsiquiatría -AEN- se ha caracterizado en sus últimas tres décadas por sus publicaciones, con la Revista de la AEN al frente, en estos últimos años el salto adelante ha sido muy significativo. Con un renovado Comité Editorial muy comprometido se han desarrollado novedades importantes, en los aspectos bibliográficos, organizativos y de contenidos. Mejoras en su composición, ISSN, formato abierto, sistema OJS, revisores, etc. han permitido constatar un progresivo flujo de trabajos, incluso un creciente número remitido desde Latinoamérica, sin olvidar el importante crecimiento en participación y acceso en índices, repositorios y bases de datos bibliográficos, prestigiando todo ello la publicación y por ende a la Asociación.

A la Revista de la AEN se le han unido otras publicaciones: Norte de salud mental, revista de amplia difusión postal y en línea, sin olvidar revistas editadas en varias comunidades autónomas: Cuadernos de Psiquiatría Comunitaria en Asturias y en Madrid el Boletín de la Asociación Madrileña de Salud Mental, así como Siso Saùde en Galicia. Son marcos de reflexión, de producción científica y de alternativas, de análisis del acontecer en el amplio campo de la salud mental, debate sobre investigaciones más recientes o el intercambio de ideas sobre nuevos espacios y experiencias. La clínica, la investigación o los aspectos de gestión, y los diferentes estamentos de la salud mental tienen este marco de expresión que permite ir acercándonos al mejor conocimiento del estado actual y lo que se hace en Salud Mental. 